\title{
Interaction of long-chain n-alcohols with fluid DOPC bilayers: a neutron diffraction study
}

\author{
Viktor I. Petrenko ${ }^{1,2}$, Maria Klacsova ${ }^{3,4}$, Anatoly I. Beskrovnyy ${ }^{1}$, Daniela Uhrikova ${ }^{4}$ \\ and Pavol Balgavy ${ }^{4}$ \\ ${ }^{1}$ Frank Laboratory of Neutron Physics, Joint Institute for Nuclear Research, Dubna, Russia \\ ${ }^{2}$ Physics Department, Kiev Taras Shevchenko National University, Kiev, Ukraine \\ ${ }^{3}$ Department of Nuclear Physics and Biophysics, Faculty of Mathematics, Physics and Informatics, Comenius University, \\ Bratislava, Slovakia \\ ${ }^{4}$ Department of Physical Chemistry of Drugs, Faculty of Pharmacy, Comenius University, Bratislava, Slovakia
}

\begin{abstract}
Lamellar phases composed of fluid dioleoylphosphatidylcholine (DOPC) bilayers containing alkan-1-ols ( $\mathrm{CnOH}, \mathrm{n}=8,10,14,16,18$ is the number of carbon atoms) at $\mathrm{CnOH}: \mathrm{DOPC}=0.3$ molar ratio and hydrated with heavy water at $20.2 \geq \mathrm{D}_{2} \mathrm{O}: \mathrm{DOPC} \geq 14.4$ molar ratio were studied by neutron diffraction. The bilayer thickness $d_{L}$ and the bilayer surface area $A_{L}$ per DOPC at the bilayer-water interface were obtained from the lamellar repeat period $d$ using molecular volumes of DOPC, $\mathrm{CnOH}$ and $\mathrm{D}_{2} \mathrm{O}$, and the Luzatti's method. Both the $d_{L}$ and $A_{L}$ increase with the $\mathrm{CnOH}$ chain length $\mathrm{n}$ at $\mathrm{CnOH}: \mathrm{DOPC}=0.3$ molar ratio: $d_{L}=(3.888 \pm 0.066)+(0.016 \pm 0.005) \cdot \mathrm{n}(\mathrm{in} \mathrm{nm})$, $A_{L}=(0.6711 \pm 0.0107)+(0.0012 \pm 0.0008) \cdot \mathrm{n}\left(\right.$ in $\left.\mathrm{nm}^{2}\right)$.
\end{abstract}

Key words: Lipid bilayer - Dioleoylphosphatidylcholine - Alkan-1-ol - Neutron diffraction

\section{Introduction}

Long-chain primary aliphatic alcohols (alkan-1-ol, abbreviation $\mathrm{CnOH}, \mathrm{n}$ is the number of carbons in the aliphatic chain) display a wide range of biocide activities (Hammond and Kubo 2000; Fujita et al. 2008). They also act as general anesthetics (Pringle et al. 1981). In drug formulations, $\mathrm{CnOHs}$ are used as transdermal drug penetration enhancers (Vávrová et al. 2005; Klimentová et al. 2006). Because the long-chain $\mathrm{CnOHs}$ are amphiphiles, they partition into lipid bilayers of biomembranes and change their structural and dynamical properties. Some of these structural perturbations might be related to biological effects of $\mathrm{CnOH}$. Consequently, effects of $\mathrm{CnOHs}$ on the structure and dynamics of model lipid membranes have been studied widely.

Correspondence to: Viktor I. Petrenko, Frank Laboratory of Neutron Physics, Joint Institute for Nuclear Research, Dubna, Russia E-mail: vip@nf.jinr.ru

Maria Klacsova, Department of Physical Chemistry of Drugs, Faculty of Pharmacy, Comenius University, Odbojárov 10, 83232 Bratislava, Slovakia

E-mail: klacsova@fpharm.uniba.sk
The fluid bilayer structural changes were studied extensively by spin label ESR, Raman and ${ }^{2} \mathrm{H}$ NMR spectroscopic techniques (Paterson et al. 1972; Horváth et al. 1980; Pope and Dubro 1986; Thewalt and Cushley 1987; Westerman et al. 1988; Westerman and Pope 1991; Raines et al. 1993). The main conclusions from these studies are the following: $i$ ) long chain $\mathrm{CnOHs}$ intercalate into fluid bilayers with alkyl chains approximately parallel to lipid acyl chains; ii) the Raman and ${ }^{2} \mathrm{H}$ NMR order parameters indicate that the packing in the bilayer hydrophobic region is influenced only slightly, in contrast to spin label ordering; iii) the $\mathrm{CnOH}$ hydroxyl group is located at or near the bilayer-water interface and anchored to hydrogen bond acceptor groups beyond the glycerol fragment. Possibly, the exact position depends on the $\mathrm{CnOH}$ chain length $\mathrm{n} ; i v$ ) in the bilayer polar region, the presence of $\mathrm{C} 8 \mathrm{OH}, \mathrm{C} 12 \mathrm{OH}$ and $\mathrm{C} 14 \mathrm{OH}$ affects the ordering at several sites with the most pronounced effect in the glycerol fragment; $v$ ) the ${ }^{2} \mathrm{H}$ NMR order parameters of 1-methylene and methyl groups of $\mathrm{CnOH}$ are dependent on the mismatch in the $\mathrm{CnOH}$ and lipid hydrophobic chain lengths.

Results of direct bilayer structure investigations in presence of $\mathrm{CnOH}$ are meager: It was found using a small-angle $\mathrm{X}$-ray diffraction $(\mathrm{SAXD})$ on the fluid lamellar $\left(L_{\alpha}\right)$ dimy- 
ristoylphosphatidylcholine (DMPC) phase at a relatively low hydration $\left(\mathrm{H}_{2} \mathrm{O}:\right.$ DMPC molar ratio $n_{W}: n_{L}=10$, mol : mol), that the increase of $\mathrm{C} 8 \mathrm{OH}$ concentration in bilayers up to $\mathrm{C} 8 \mathrm{OH}: \mathrm{DMPC}=1.5$ molar ratio results in the lamellar repeat period $(d)$ decrease; simultaneously, the surface area per lipid molecule at the bilayer/water interface $\left(A_{L}\right)$ increases but the bilayer thickness $d_{L}$ remains approximately constant (Pope et al. 1984). On the other hand, molecular dynamics (MD) simulations of the fluid DMPC bilayers predict an increase in the thickness and a decrease in the surface area for $\mathrm{C} 8 \mathrm{OH}$, $\mathrm{C} 10 \mathrm{OH}$ and $\mathrm{C} 14 \mathrm{OH}$ homologs (Griepernau et al. 2007). Dipalmitoylphosphatidylcholine (DPPC) and $\mathrm{CnOHs}(\mathrm{n}=$ 8-18) form mixed lamellar solid-like $L_{\beta}$ and fluid $L_{\alpha}$ phases at $\mathrm{CnOH}: \mathrm{DPPC}=0.4$ molar ratio and intermediate hydration $\left(\mathrm{H}_{2} \mathrm{O}: \mathrm{DPPC}=10\right.$, mol : mol); both the $L_{\beta} \rightarrow L_{\alpha}$ phase transition temperature $t_{m}$ and surface area $A_{L}$ in the $L_{\beta}$ phase increase with the $\mathrm{CnOH}$ chain length $\mathrm{n}$, but two different $L_{\alpha}$ phases coexist above $t_{m}$ what precluded determination of bilayer structural parameters in the biologically more relevant fluid phase (Lukešová et al. 2007). Using SAXD and wide-angle X-ray diffraction (WAXD), we have found that dioleoylphosphatidylcholine (DOPC) and $\mathrm{CnOHs}(\mathrm{n}=$ 8-18) form homogeneous $L_{\alpha}$ phases without phase separation at least to $\mathrm{CnOH}:$ DOPC molar ratio $n_{\mathrm{CnOH}}: n_{L}=0.4: 1$ (Kotalová et al. 2008). These phases can be used to obtain the thickness $d_{L}$ and surface area $A_{L}$ in biologically relevant fluid bilayers. This is the aim of present study. For the $d_{L}$ and $A_{L}$ determination, we use the time-of-flight small-angle neutron diffraction (SAND).

\section{Materials and Methods}

Synthetic DOPC was purchased from Avanti Polar Lipids (Alabaster, USA) and used as received. Alkan-1-ols $(\mathrm{CnOH}$, $\mathrm{n}=8,10,14,16,18)$ with $99 \%$ purity were purchased from Sigma (St. Luis, USA). The organic solvents of spectral purity were obtained from Slavus (Bratislava, Slovakia). Solvents were redistilled before use. Heavy water $\left(99.9 \%{ }^{2} \mathrm{H}_{2} \mathrm{O}\right)$ was obtained from Merck (Darmstadt, Germany).

The required amounts of DOPC and $\mathrm{CnOH}$ were dissolved in methanol-chloroform solvent and mixed in a thinwalled quartz tube to obtain the needed $n_{\mathrm{CnOH}}: n_{L}$ molar ratio. The solvent was then evaporated under a stream of gaseous nitrogen for $\sim 40 \mathrm{~min}$ and its traces removed by an oil vacuum pump ( $\sim 7$ hours). To prevent evaporation of $\mathrm{CnOHs}$, samples were cooled down to $-15^{\circ} \mathrm{C}$ during evacuation. The dried samples were hydrated with heavy water. The exact value of heavy water : DOPC $=n_{W}: n_{L}$ molar ratio was obtained from gravimetry. Then the quartz tubes were flame-sealed and their content homogenized by repeated forth-and-back centrifugation. Before diffraction experiments, the samples were equilibrated at room temperature for 12 hours. For SAXD/WAXD experiments, the hydrated $\mathrm{DOPC}+\mathrm{CnOH}$ mixture was placed between two Kapton foils (Dupont, France), which constitute the windows of the sample holder.

The SAXD and WAXD experiments were performed at beamline A2 in HASYLAB at DESY, Hamburg (http://hasylab.desy.de/facilities/doris_iii/beamlines/e5748/index_eng. html). The evacuated double-focusing camera was equipped with two linear delay line readout detectors (Gabriel 1977, Rapp et al. 1995). The SAX detector was calibrated using rattail tendon (Bigi and Roveri 1991) and the WAX detector by tripalmitin (Chapman 1962, Kellens et al. 1990). The raw data were normalized against the incident beam intensity using the signal of the ionization chamber. Data reduction and normalization were done with the programs STAFO and OTOKO (Boulin et al. 1986).

The SAND experiment was carried out on the DN-2 multipurpose neutron diffractometer (Balagurov 1991), equipped with a two-dimensional position-sensitive detector, at the IBR-2 high-flux pulse reactor in Frank Laboratory of Neutron Physics, Joint Institute for Nuclear Research, Dubna, Russia (http://flnp.jinr.ru/137). The reactor power was $1 \mathrm{MW}$, the pulse frequency $5 \mathrm{~Hz}$, and the integral neutron flux on sample $\sim 1.0 \cdot 10^{7} \mathrm{~cm}^{-2} . \mathrm{s}^{-1}$. The sample temperature was $18.0^{\circ} \mathrm{C}$. The time-of-flight diffraction technique was used (Aksenov and Balagurov 1996). The Bragg angle was kept constant $\left(4^{\circ}\right)$ and the wavelength of the neutron beam varied from $0.1 \mathrm{~nm}$ to $1.0 \mathrm{~nm}$ during each pulse. The counts of diffracted neutrons $v s$. time scans were accumulated and superposed, and translated into the scale of intensity $v s$. reciprocal spacing. The reciprocal spacing was calibrated using the diffraction peak of $\mathrm{TlGaSe}_{2}$ single crystal with $d_{(002)}=0.7698 \mathrm{~nm}$ (Henkel et al. 1982). The lamellar repeat period $d$ was obtained from the position of the first order $L_{\alpha}$ phase diffraction peak in the reciprocal space with the accuracy $\pm 0.001 \mathrm{~nm}$.

\section{Results and Discussion}

It is well known that the fully hydrated DOPC forms the fluid lamellar $L_{\alpha}$ phase at temperature above $-17.3^{\circ} \mathrm{C}$ (Lewis et al. 1988, Pan et al. 2008). We have confirmed this using SAXD and WAXD experiments. For samples hydrated at $n_{W}: n_{L}=$ 50 : 1 molar ratio, we have obtained SAXD patterns typical of an one-dimensional lamellar phase with equidistant lipid bilayers separated by aqueous layers in a wide temperature range $20-50^{\circ} \mathrm{C}$. As an example, the SAXD pattern observed at $20^{\circ} \mathrm{C}$ is shown in Fig. 1A. Using the Bragg equation, the repeat period $d$ of lamellar phase was determined from the position of the first-order diffraction peak in the reciprocal space. At $20^{\circ} \mathrm{C}$, we observed $d=6.4 \mathrm{~nm}$, close to $d=6.3 \mathrm{~nm}$ obtained by Pan et al. (2008) at 15 and $30^{\circ} \mathrm{C}$. The WAXD 
pattern consisted of a broad band characteristic of a phase wherein the hydrocarbon chains are melted and arranged in a quasi-hexagonal disordered lattice (Luzzati 1968). Similar SAXD and WAXD patterns as described above were observed for hydrated $\mathrm{DOPC}+\mathrm{CnOH}$ mixtures up to $n_{\mathrm{CnOH}}$ : $n_{D O P C}=0.4: 1$ molar ratios (Fig. 1 ). We conclude that DOPC and $\mathrm{CnOHs}$ form homogeneous $L_{\alpha}$ phases without phase separation at least to $\mathrm{CnOH}$ : DOPC molar ratio $n_{\mathrm{CnOH}}$ : $n_{L}=0.4: 1$.

The samples for SAXD and WAXD experiments were prepared at $n_{W}: n_{L}=50: 1$ molar ratio. It is well known that different types of water molecules exist in the $L_{\alpha}$ phase of phosphatidylcholines (see Národa et al. (1983) and Gawrisch et al. (1985) for references). First 12 molecules per lipid move anisotropically due to interactions with the bilayer polar region and form the main hydration shell. Next 11-12 molecules per lipid are trapped between equidistant bilayers, their motion is isotropic but they exchange rapidly with molecules in the main shell. If more than 23-24 water molecules per lipid are present in the sample, they begin to form a separate aqueous phase. The bilayer structural parameters and ordering are influenced strongly by lateral stress and interbilayer forces at $n_{W}: n_{L} \leq 12 \pm 1$, and the bilayers become curved and thus the $L_{\alpha}$ phase contains water-filled defects at $n_{W}: n_{L} \geq 23 \pm 1$ (Gawrisch et al. 1985; Gallová et al. 1995; Balgavý et al. 1998; Karlovská et al. 2004). Consequently, the bilayer structural parameters obtained from the repeat period $d$ at $12 \pm 1 \geq n_{W}: n_{L} \geq 23 \pm 1$ molar ratios can be thus flawed. This is why we have not continued in further SAXD data evaluation.

The composition of samples prepared as estimated by gravimetry and the lamellar repeat period $d$ measured by SAND are shown in Table 1. Our recent small-angle neutron scattering (SANS) experiments confirmed that the number of water molecules per lipid located in the bilayer polar region increases by one water molecule due to the presence of $\mathrm{CnOH}$ at $n_{\mathrm{CnOH}}: n_{L}=0.4$ molar ratio (Klacsová et al. 2010a). It follows from the arguments above, that the $n_{W}: n_{L}=14.4 \div 20.2$ hydration level used in the present work in SAND experiment (Table 1) ensure that the surface area $A_{L}$, the thickness $d_{L}$

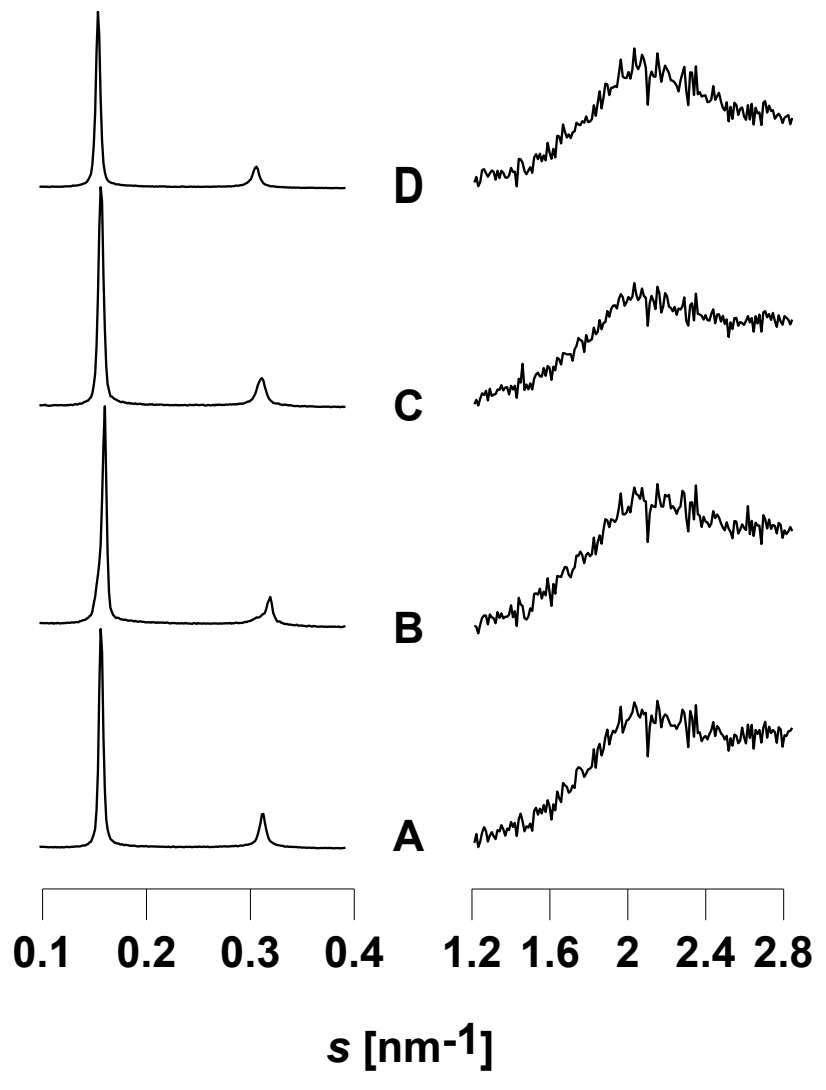

Figure 1. SAXD (left) and WAXD (right) patterns of hydrated DOPC (A), and DOPC + C8OH (B), DOPC + C12OH (C) and $\mathrm{DOPC}+\mathrm{C} 16 \mathrm{OH}$ mixtures at $20.0^{\circ} \mathrm{C}$

and the coplanarity of bilayers should not be affected by the hydration overly. Under these conditions, the repeat period $d$ measured (Table 1) is the sum of bilayer thickness $d_{L}$ and water layer thickness $d_{W}$ between bilayers in the $L_{\alpha}$ phase:

$$
d=d_{L}+d_{W}
$$

Luzzati (1968) proposed a simple and much used method to obtain $A_{L}$ and $d_{L}$ from the repeat period. The method is

Table 1. Composition of DOPC $+\mathrm{CnOH}$ samples - water : lipid molar ratio $n_{W}: n_{L}$, alcohol : lipid molar ratio $n_{\mathrm{CnOH}}: n_{L}$, repeat period $d$, and molecular volumes of lipid $V_{L}$ and alcohol $V_{\mathrm{CnOH}}$

\begin{tabular}{lccccc}
\hline Sample & $n_{W}: n_{L}$ & $n_{\mathrm{CnOH}}: n_{L}$ & $d(\mathrm{~nm})$ & $V_{L}\left(\mathrm{~nm}^{3}\right)$ & $V_{C n O H}\left(\mathrm{~nm}^{3}\right)$ \\
\hline DOPC & 20.1 & - & 6.03 & $1.292 \pm 0.002$ & - \\
DOPC + C8OH & 19.7 & 0.3 & 5.70 & $1.292 \pm 0.002$ & $0.248 \pm 0.008$ \\
DOPC + C10OH & 14.4 & 0.3 & 5.37 & $1.292 \pm 0.002$ & $0.302 \pm 0.005$ \\
DOPC + C12OH & 20.0 & 0.3 & 5.81 & $1.292 \pm 0.002$ & $0.356 \pm 0.004$ \\
DOPC + C14OH & 19.6 & 0.3 & 5.86 & $1.292 \pm 0.002$ & $0.409 \pm 0.004$ \\
DOPC + C16OH & 20.0 & 0.3 & 5.84 & $1.292 \pm 0.002$ & $0.463 \pm 0.005$ \\
DOPC + C18OH & 20.2 & 0.3 & 5.94 & $1.292 \pm 0.002$ & $0.516 \pm 0.008$ \\
\hline
\end{tabular}




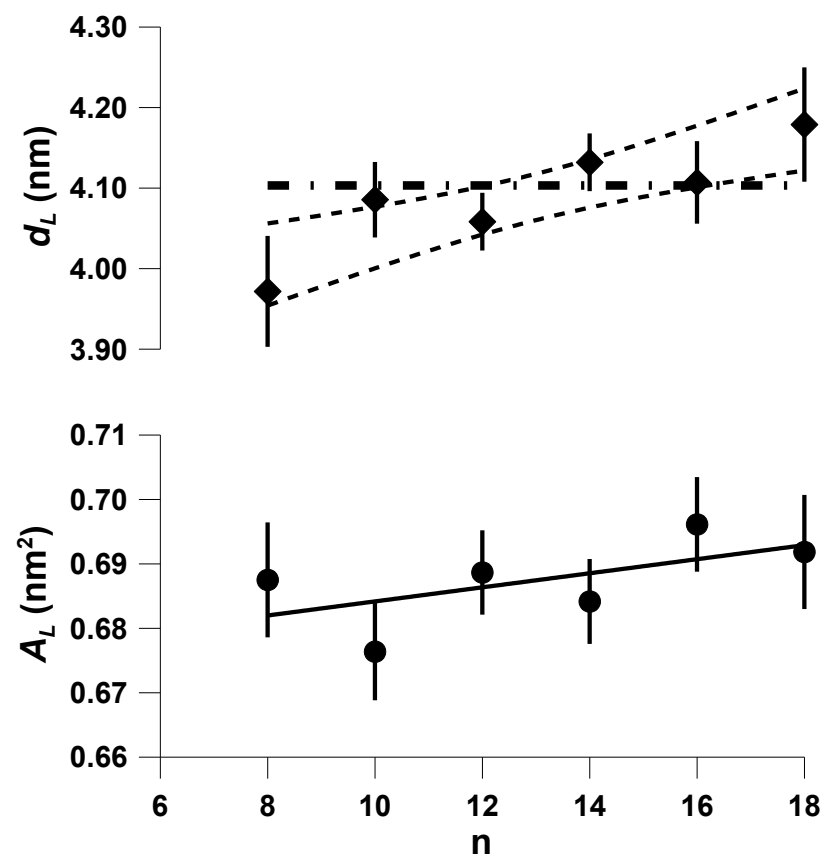

Figure 2. Dependence of the bilayer thickness $d_{L}(\diamond)$ and of the surface area $A_{L}(\bullet)$ on the $\mathrm{CnOH}$ chain length $\mathrm{n}$ at $\mathrm{CnOH}: \mathrm{DOPC}=$ 0.3 molar ratio. Dash-dotted line, bilayer thickness $d_{L}$ in control DOPC sample without $\mathrm{CnOH}$; dashed lines, $90 \%$ confidence interval of bilayer thickness values $d_{L}$ in $\mathrm{DOPC}+\mathrm{CnOH}$ samples.

based on assumptions, that the volumes of bilayer and water in the $L_{\alpha}$ phase are known and that the bilayer itself does not contain any water molecules. It follows from these assumptions that for $L_{\alpha}$ phases studied in the present work the $d A_{L}$ product can be written as

$$
\begin{aligned}
& d A_{L}=d_{L} A_{L}+d_{W} A_{L}=2\left(V_{L}+V_{C n O H} n_{C n O H} /\right. \\
& \left./ n_{L}+V_{W} n_{W} / n_{L}\right)
\end{aligned}
$$

where $V_{L}, V_{\mathrm{CnOH}}$ and $V_{W}$ is the molecular volume of DOPC, $\mathrm{CnOH}$ and water, respectively, and $n_{\mathrm{CnOH}} / n_{L}$ and $n_{W} / n_{L}$ are the $\mathrm{CnOH}$ : DOPC and water : DOPC molar ratios, respectively. The $V_{L}$ and $V_{\mathrm{CnOH}}$ volumes are shown in Table 1 . They were calculated using the experimental apparent molecular volumes $V_{D O P C}=1.2940 \mathrm{~nm}^{3}$ and $V_{C 10 O H}=0.3094 \mathrm{~nm}^{3}$, $V_{\mathrm{C12OH}}=0.3533 \mathrm{~nm}^{3}, V_{\mathrm{Cl} 14 \mathrm{OH}}=0.4193 \mathrm{~nm}^{3}, V_{\mathrm{Cl6OH}}=$ $0.4685 \mathrm{~nm}^{3},(\mathrm{n}=10,12,14,16)$ in bilayers measured at $20^{\circ} \mathrm{C}$ (DOPC) and at $38^{\circ} \mathrm{C}(\mathrm{CnOH})$, respectively (Klacsová et al. 2010b), and corrected for the temperature shift using the coefficient of thermal isobaric volume expansivity

$$
\gamma_{i}=\left(\partial V_{i} / \partial T\right) / V_{i}
$$

where $T$ is the absolute temperature and $i=D O P C$ or $\mathrm{CnOH}$. The experimental values $\gamma_{D O P C}=65.7 \cdot 10^{-5} \mathrm{~K}^{-1}, \gamma_{C 10 O H}=$
$68.8 \cdot 10^{-5} \mathrm{~K}^{-1}, \gamma_{\mathrm{C} 12 \mathrm{OH}}=67.9 \cdot 10^{-5} \mathrm{~K}^{-1}, \gamma_{\mathrm{C} 14 \mathrm{OH}}=68.4 \cdot 10^{-5} \mathrm{~K}^{-1}$ and $\gamma_{\mathrm{C} 16 \mathrm{OH}}=69.7 \cdot 10^{-5} \mathrm{~K}^{-1}$ found recently (Klacsová et al. $2010 \mathrm{~b}$ ) were used. The corrected $V_{\mathrm{CnOH}}$ values $v s$. the chain length $\mathrm{n}$ of $\mathrm{CnOH}$ were fitted by a linear function $\left(\mathrm{r}^{2}=\right.$ 0.994) and then the resulting apparent molecular volumes shown in Table 1 were obtained from this linear function. The errors shown in Table 1 were obtained from Klacsová et al. (2010b) for $V_{D O P C}$ and from the linear fit for $V_{\mathrm{CnOH}}$. The molecular volume $V_{W}=0.03008 \mathrm{~nm}^{3}$ was calculated from the isotope composition of heavy water used and molar volume data for $\mathrm{H}_{2} \mathrm{O}$ and $\mathrm{D}_{2} \mathrm{O}$ at $18^{\circ} \mathrm{C}$ published by Lemmon et al. (2010).

Using Eq. (2) and the data in Table 1, the surface area value $A_{L}=0.629 \pm 0.006 \mathrm{~nm}^{2}$ was obtained for DOPC bilayers without $\mathrm{CnOH}$. Probably the most reliable present "benchmark" value for fully hydrated DOPC bilayers is $A_{L}=$ $0.669 \pm 0.010 \mathrm{~nm}^{2}$ at $30^{\circ} \mathrm{C}$ (Kučerka et al. 2009). It was obtained by a simultaneous analysis of synchrotron radiation and contrast variation neutron scatterings on extruded 60 nm unilamellar vesicles (ULVs). To compare the $A_{L}$ values above, we corrected the surface area in ULVs for lateral expansivity by

$$
\beta=\left(\partial A_{L} / \partial T\right) / A_{L}
$$

using the value $\beta=0.003 \mathrm{~K}^{-1}$ published by Nagle and Tristram-Nagle (2000). The corrected value is $A_{L}=0.645 \pm 0.010$ $\mathrm{nm}^{2}$; the value found in the present work is thus smaller by $A_{L}(U L V)-A_{L}\left(L_{\alpha}\right)=0.016 \pm 0.012 \mathrm{~nm}^{2}$, where $A_{L}(U L V)$ is the surface area in ULVs (after adjustment to temperature effect) and $A_{L}\left(L_{\alpha}\right)$ that in the $L_{\alpha}$ phase (present work), respectively. Further correction for bilayer fluctuations would increase $A_{L}\left(L_{\alpha}\right)$ by about $0.02 \mathrm{~nm}^{2}$ (Nagle and TristramNagle 2000) resulting in the coincidence of $A_{L}(U L V)$ and $A_{L}\left(L_{\alpha}\right)$ within error margins. This is surprisingly good result considering the simplicity of Luzzati's method.

The value of surface area per single DOPC molecule in the presence of $\mathrm{CnOH}$ in fluid $L_{\alpha}$ phase bilayers are shown in Fig. 2 as a function of $\mathrm{CnOH}$ chain length n. For the all $\mathrm{CnOH}$ homologs, the $A_{L}$ values are larger than in control DOPC bilayers without $\mathrm{CnOH}$ added. The surface area increases from $A_{L}=0.688 \pm 0.009 \mathrm{~nm}^{2}$ for $\mathrm{C} 8 \mathrm{OH}$ to $A_{L}=$ $0.692 \pm 0.009 \mathrm{~nm}^{2}$ for $\mathrm{C} 18 \mathrm{OH}$. Pope et al. (1984) found that the surface area $A_{L}$ in fluid DMPC bilayers increases with the increase of $\mathrm{C} 8 \mathrm{OH}$ concentration in bilayers at $n_{W}: n_{L}=10$ hydration. After recalculation of their data, we found that this increase corresponds to about $\Delta A_{L}=$ $0.050 \pm 0.008 \mathrm{~nm}^{2}$ at $n_{\mathrm{C} 8 \mathrm{OH}} / n_{L}=0.3$ molar ratio, in excellent agreement with $\Delta A_{L}=0.058 \pm 0.011 \mathrm{~nm}^{2}$ at the same molar ratio in the present work. Our experimental data in Fig. 2 can be approximated by a linear function giving the dependence $A_{L}=(0.6711 \pm 0.0107)+(0.0012 \pm 0.0008) \cdot \mathrm{n}$ in $\mathrm{nm}^{2}$. We fitted also the $\mathrm{C} 8 \mathrm{OH}, \mathrm{C} 10 \mathrm{OH}$ and $\mathrm{C} 14 \mathrm{OH}+$ 
DMPC data obtained by Griepernau et al. (2007) using MD simulations at $n_{W}: n_{L} \geq 39$ hydration. We obtained $\left(\right.$ in $\left.\mathrm{nm}^{2}\right) A_{L}=(0.6312 \pm 0.0028)+(0.0007 \pm 0.0002) \cdot \mathrm{n}$ for $n_{\mathrm{CnOH}}: n_{L}=0.0625, A_{L}=(0.6599 \pm 0.0022)-(0.0032 \pm$ $0.0002) \cdot \mathrm{n}$ for $n_{\mathrm{CnOH}}: n_{L}=0.1875$ and $A_{L}=(0.6765 \pm$ $0.0282)-(0.0053 \pm 0.0026) \cdot \mathrm{n}$ for $n_{\mathrm{CnOH}}: n_{L}=0.5625$ from their data. It is evident that the simulation results are qualitatively in accord with our experiment at the lowest $n_{\mathrm{CnOH}}: n_{L}=0.0625$ molar ratio.

The value of lipid surface area $A_{L}$ is the result of attractive and repulsive forces acting at the aqueous phase-bilayer interface. The main attractive components are the van der Waals forces between acyl chains and head group dipolar interactions, and the main repulsive components include steric interactions, hydration forces, and entropic contributions due to acyl chain ordering; the equilibrium area $A_{L}$ is given by the balance of these forces that minimizes the interfacial free energy. Amphiphilic admixtures influence this delicate balance. In case of homologous series with long chain hydrocarbon substituents at a fixed admixture : lipid molar ratio in the bilayer, the dependence of $A_{L}$ on the chain length $\mathrm{n}$ can be monotonously increasing as found for $\mathrm{CnOHs}$ in the present work, but can be also biphasic. For example, Uhríková et al. (2002) observed the maximum of $A_{L}$ in the dipalmitoylphosphatidylcholine (DPPC) $L_{\alpha}$ phase for the alkyloxy chain length $n=9-10$ carbons of intercalated tertiary amine local anesthetics (monohydrochlorides of [2-(alkyloxy)phenyl]-2-(1-piperidynyl)ethyls esters of carbamic acid, $\mathrm{n}=3 \div 13$ ), Dubničková et al. (2004) in the egg yolk phosphatidylcholine (EYPC) $L_{\alpha}$ phase for the alkyl chain length $\mathrm{n}=9-10$ of gemini surfactants $(1,4-$ butanediamonium- $N, N^{\prime}$-dialkyl- $N, N, N^{\prime}, N^{\prime}$-tetramethyl dibromides $n=7 \div 16$ ), and Karlovská et al. (2004) in the EYPC $L_{\alpha}$ phase for the alkyl chain length $\mathrm{n}=8$ of $N$-alkyl$N, N$-dimethylamine- $N$-oxides $(\mathrm{n}=6 \div 18)$. It follows from this comparison, that not only the hydrocarbon chain but also the structure of polar fragment influences lateral interactions strongly.

The bilayer thickness was calculated according to Luzzati (1968) as

$$
\begin{aligned}
& d_{L}=d-d_{W}=d-2 V_{W} n_{W} / n_{L} A_{L}=d\left[1-\left(V_{W} n_{W} / n_{L}\right):\right. \\
& \left.\left(V_{L}+V_{C n O H} n_{C n O H} / n_{L}+V_{W} n_{W} / n_{L}\right)\right]
\end{aligned}
$$

This equation is based on an assumption that all the water molecules are located in aqueous layers between lipid bilayers in the $L_{\alpha}$ phase. Using this equation and the data in Table 1, we obtained the bilayer thickness $d_{L}=4.10 \pm 0.07$ $\mathrm{nm}$ for DOPC bilayers without $\mathrm{CnOH}$. To compare this value with the most reliable present "benchmark" value for fully hydrated DOPC bilayers at $30^{\circ} \mathrm{C}$ obtained by a simultaneous analysis of synchrotron radiation and contrast variation neutron scatterings on extruded $60 \mathrm{~nm}$ ULVs (Kučerka et al. 2009), we corrected the surface area in the $L_{\alpha}$ phase for lateral expansivity by

$$
\alpha=\left(\partial d_{L} / \partial T\right) / d_{L}
$$

using the value $\alpha=-2.68 \cdot 10^{-3} \mathrm{~K}^{-1}$ found recently by Klacsová et al. (2010a). The corrected value is $d_{L}=3.97 \pm 0.07$ $\mathrm{nm}$ at $30^{\circ} \mathrm{C}$, very close to the value $d_{L}=3.89 \pm 0.08 \mathrm{~nm}$ found in ULVs at this temperature. The values of bilayer thickness in presence of $\mathrm{CnOH}$ in fluid $L_{\alpha}$ phase are shown in Fig. 2 as a function of $\mathrm{CnOH}$ chain length $\mathrm{n}$. The bilayer thickness increases from $d_{L}=3.97 \pm 0.10 \mathrm{~nm}$ for $\mathrm{C} 8 \mathrm{OH}$ to $d_{L}=4.18 \pm 0.10 \mathrm{~nm}$ for $\mathrm{C} 18 \mathrm{OH}$. Griepernau et al. (2007) have obtained from their MD simulations of $\mathrm{C} 8 \mathrm{OH}, \mathrm{C} 10 \mathrm{OH}$ and $\mathrm{C} 14 \mathrm{OH}+\mathrm{DMPC}$ bilayers at $n_{W}: n_{L} \geq 39$ hydration an increase in bilayer thickness with $\mathrm{n}$ for $n_{\mathrm{CnOH}}: n_{L}=0.1875$ and $n_{\mathrm{CnOH}}: n_{L}=0.5625$, but no changes were observed for lower $n_{\mathrm{CnOH}}: n_{\mathrm{L}}=0.0625$ molar ratio. Our results are at variance with results of Pope et al. (1984) who found that the bilayer thickness $d_{L}$ in fluid DMPC bilayers remains approximately constant with the increase of $\mathrm{C} 8 \mathrm{OH}$ concentration in bilayers at $n_{W}: n_{L}=10$ hydration. The cause of this difference could be the low hydration level. With the insertion of $\mathrm{C} 8 \mathrm{OH}$, the bilayer surface area increases but the hydration remains constant. This should produce a lateral compression that increases the thickness (Gallová et al. 1995; Balgavý et al. 1998; Karlovská et al. 2004). The mismatch between the $\mathrm{CnOH}$ and DMPC hydrocarbon chain lengths should result in a thickness decrease in nonstressed bilayers (Balgavý and Devínsky 1996), but the lateral compression due to low hydration level acts in the opposite direction. This is the most probable cause of the strange thickness dependence in the paper of Pope et al. (1984).

The experimental data in Fig. 2 can be fitted by a linear function giving the dependence $d_{L}=(3.888 \pm 0.066)+$ $(0.016 \pm 0.005) \cdot \mathrm{n}$ in $\mathrm{nm}$. The $90 \%$ confidence interval for $d_{L}$ is shown in Fig. 2 (dashed lines) to compare with the $d_{L}$ value in control DOPC sample without $\mathrm{CnOH}$ (dash-dotted line). These results indicate, that with the increase of the $\mathrm{CnOH}$ chain length $\mathrm{n}$ the bilayer thickness approximates the control value and, eventually, exceeding it at some value of $n$. Unfortunately, the relatively large experimental errors and the scatter of $d_{L}$ data preclude more quantitative conclusions - the cross over point can be located at $n=12$ as well as at $\mathrm{n}=16$. In any case the dependence in Fig. 2 is in accord with the postulate that the bilayer thickness change due to length difference between admixture and lipid hydrocarbon chains should diminish with this difference decrease (Balgavý and Devínsky 1996).

It is well known that the activity of the sarcoplasmic reticulum $\mathrm{Mg}^{2+}$-dependent $\mathrm{Ca}^{2+}$-transporting ATPase (SERCA, ATP phosphohydrolase, EC 3.6.1.38) can be modulated by physical properties of surrounding bilayer. The maximum 
of its specific activity was observed when reconstituted in bilayers of DOPC while phosphatidylcholines with shorter or longer acyl chains supported progressively decreasing activities (see Karlovská et al. (2006) for references). The chain length dependence of SERCA specific activity is frequently explained by the hydrophobic mismatch hypothesis: it is supposed that the thickness of the hydrophobic region of the bilayer must match the length of the hydrophobic part of protein to support its optimal function; increasing or decreasing of this thickness should cause conformation changes resulting in case of a reduced SERCA phosphohydrolase activity and $\mathrm{Ca}^{2+}$ transport. Recently, Karlovská et al. (2008) have observed that when the SERCA was reconstituted into DOPC, $\mathrm{C} 18 \mathrm{OH}$ stimulated its activity from $26.1 \pm 3.2 \mathrm{IU} / \mathrm{mg}$ to $37.4 \pm 0.5 \mathrm{IU} / \mathrm{mg}$ in the range of $n_{\mathrm{C} 18 \mathrm{OH}}$ : $n_{L}=0 \div 1.0$ molar ratios. This result is surprising because $\mathrm{C} 18 \mathrm{OH}$ slightly increases the bilayer thickness as found in the present study (Fig. 2), one would expect rather inhibition of the ATPase activity according to hydrophobic mismatch hypothesis. We plan therefore to extend our studies in order to find which bilayer physical properties are responsible for the ATPase activity modulation by $\mathrm{CnOHs}$. In conclusion, we have observed that both the bilayer thickness and the lipid surface area increase with the chain length of alcohols located in bilayers of the fluid DOPC lamellar phase. The results presented here could help to better understand amphiphile drug - membrane interactions, in particular protein functions, which are sensitive to bilayer structural properties that the drugs are able to modulate.

Acknowledgement. This work was supported by the VEGA 1/0295/ 08 grant, by the JINR project $074-106931-909 / 211$ and by the EC FP7/2007-2013 Programme under grant agreement No. 226716. We thank Dr. S. S. Funari from Hasylab at DESY in Hamburg for help with SAXD/WAXD experiments.

\section{References}

Aksenov V. L., Balagurov A. M. (1996): Neutron time-of-flight diffractometry. Phys. Usp. 39, 897-924; doi:10.1070/PU1996v039n09ABEH000169

Balagurov A. M. (1991): New diffractometers at the IBR-2 high-flux pulsed reactor. Physica B 174, 542-545; doi:10.1016/09214526(91)90654-W

Balgavý P., Devínsky F. (1996): Cut-off effects in biological activities of surfactants. Adv. Colloid Interface Sci. 66, 23-63; doi:10.1016/0001-8686(96)00295-3

Balgavý P., Dubničková M., Uhríková D., Yaradaikin S., Kiselev M., Gordeliy V. (1998): Bilayer thickness in unilamellar extruded egg yolk phosphatidylcholine liposomes: a small angle neutron scattering study. Acta Phys. Slov. 48, 509-533

Bigi A., Roveri N. (1991): Fibre diffraction: collagen. In: Handbook on Synchrotron Radiation. (Eds. S. Ebashi, M. Koch and
E. Rubenstein), pp. 199-239, Elsevier Science Publishers B.V., Amsterdam

Boulin C., Kempf R., Koch M. H. J., McLaughlin S. M. (1986): Data appraisal, evaluation and display for synchrotron radiation experiments: hardware and software. Nucl. Instrum. Methods Phys. Res. A 249, 399-407; doi:10.1016/01689002(86)90694-7

Chapman D. (1962): The polymorphism of glycerides. Chem. Rev. 62, 433-453; doi:10.1021/cr60219a003

Dubničková M., Yaradaikin S., Lacko I., Devínsky F., Gordeliy V., Balgavý P. (2004): Effects of gemini surfactants on egg phosphatidylcholine bilayers in the fluid lamellar phase. Colloids Surf. B 34, 161-164; doi:10.1016/j.colsurfb.2003.12.009

Fujita K.-I., Fujita T., Kubo I. (2008): Antifungal activity of alkanols against Zygosaccharomyces bailii and their effects on fungal plasma membrane. Phytotherapy Res. 22, 1349-1355; doi:10.1002/ptr.2500

Gabriel A. (1977): Position sensitive X-ray detectors. Rev. Sci. Instrum. 48, 1303-1305; doi:10.1063/1.1134870

Gallová J., Andriamainty F., Balgavý P. (1995): Spin probe ESR study of the hydration of oriented egg yolk phosphatidylcholine bilayers. Acta Phys. Slov. 45, 193-204

Gawrisch K., Richter W., Möpps A., Balgavý P., Arnold K., Klose G. (1985): The influence of water concentration on the structure of egg yolk phospholipid/water dispersions. Stud. Biophys. 108, 5-16

Griepernau B., Leis S., Schneider M. F., Sikor M., Steppich D., Bockmann R. A. (2007): 1-Alkanols and membranes: a story of attraction. Biochim. Biophys. Acta 1768, 2899-2913; doi:10.1016/j.bbamem.2007.08.002

Hammond D. G., Kubo I. (2000): Alkanols inhibit respiration of intact mitochondria and display cutoff similar to that measured in vivo. J. Pharmacol. Exp. Ther. 293, 822-828

Henkel W., Hochheimer H. D., Carlone C., Werner A., Ves S., Schnering H. G. (1982): High-pressure Raman study of the ternary chalcogenides TlGaS2, TlGaSe2, TlinS2, and TlInSe2. Phys. Rev. B 26, 3211-3221; doi:10.1103/PhysRevB.26.3211

Horváth L. I., Cirák J., Vigh L. (1980): Relation or Raman order parameters to spin labeling parameters. Chem. Phys. Lipids 27, 237-250; doi:10.1016/0009-3084(80)90039-0

Karlovská J., Chnápková S., Balgavý P. (2008): Effect of octadecan1-ol on the activity of $\mathrm{Ca}^{2+}-\mathrm{Mg}^{2+}$-ATPase reconstituted in DOPC vesicles. Acta Facult. Pharm. Univ. Comenianae $\mathbf{5 5}, 115-121$

Karlovská J., Lohner K., Degovics G., Lacko I., Devínsky F., Balgavý P. (2004): Effects of non-ionic surfactants N-alkyl-N,Ndimethylamine- $\mathrm{N}$-oxides on the structure of a phospholipid bilayer: small-angle X-ray diffraction study. Chem. Phys. Lipids 129, 31-41; doi:10.1016/j.chemphyslip.2003.11.003

Karlovská J., Uhríková D., Kučerka N., Teixeira J., Devínsky F., Lacko I., Balgavý P. (2006): Influence of N-dodecyl-N,N-dimethylamine-N-oxide on the activity of sarcoplasmic reticulum $\mathrm{Ca}^{2+}$-transporting ATPase reconstituted into diacylphosphatidylcholine vesicles: effects of bilayer physical parameters. Biophys. Chem. 119, 69-77; doi:10.1016/j.bpc.2005.09.007 
Kellens M., Meeussen W., Reynaers H. (1990): Crystallization and phase-transition studies of tripalmitin. Chem. Phys. Lipids 55, 163-178; doi:10.1016/0009-3084(90)90077-5

Klacsová M., Uhríková D., Kučerka N., Teixeira J., Zajac P., Balgavý P. (2010a): Effects of aliphatic alcohols on the fluid bilayer in unilamellar DOPC+DOPS vesicles as determined by a small-angle neutron scattering. Biochim. Biophys. Acta (in press)

Klacsová M., Westh P., Balgavý P. (2010b): Molecular and component volumes of saturated n-alkanols in DOPC+DOPS bilayers. Chem. Phys. Lipids 163, 498-505; doi:10.1016/ j.chemphyslip.2010.04.004

Klimentová J., Kosák P., Vávrová K., Holas T., Hrabálek A. (2006): Influence of terminal branching on the transdermal permeation-enhancing activity in fatty alcohols and acids. Bioorg. Med. Chem. 14, 7681-7687; doi:10.1016/ j.bmc.2006.08.013

Kotalová M., Uhríková D., Funari S. S., Balgavý P. (2008): Influence of long-chain alcohols on structural parameters of DOPC bilayers. In: HASYLAB Annual Report 2007. (Eds. W. Caliebe, W. Drube and J.R. Schneider), pp. 1485-1486, DESY, Hamburg

Kučerka N., Gallová J., Uhríková D., Balgavý P., Bulacu M., Marrink S.-J., Katsaras J. (2009): Areas of monounsaturated phosphatidylcholines. Biophys. J. 97, 1926-1932; doi:10.1016/j.bpj.2009.06.050

Lemmon E. W., McLinden M. O., Friend D. G. (2010): Thermophysical properties of fluid systems. In: NIST Chemistry WebBook, NIST Standard Reference Database Number 69. (Eds. P.J. Linstrom and W.G. Mallard), National Institute of Standards and Technology, Gaithersburg MD, 20899, USA http://webbook.nist.gov (retrieved March 06, 2010)

Lewis R. N., Sykes B. D., McElhaney R. N. (1988): Thermotropic phase behavior of model membranes composed of phosphatidylcholines containing cis-monounsaturated acyl chain homologues of oleic acid: differential scanning calorimetric and 31P-NMR spectroscopic studies. Biochemistry 27, 880-887; doi:10.1021/bi00403a007

Lukešová M., Uhríková D., Kotalová M., Balgavý P. (2007): Effect of normal alcohols on the lipid bilayer structure in hydrated lamellar dipalmitoylphosphatidylcholine gel phase. Farm. Obzor 76, 236-244 (in Slovak)

Luzzati V. (1968): X-ray diffraction studies of lipid-water systems. In: Biological Membranes. (Ed. D. Chapman), pp. 71-124, Academic Press, London, New York

Nagle J. F., Tristram-Nagle S. (2000): Structure of lipid bilayers. Biochim. Biophys. Acta 1469, 159-195

Národa J., Balgavý P., Gawrisch K., Čižmárik J. (1983): Effect of the local anesthetic heptacaine hydrochloride on the structured water in model phosphatidylcholine membrane: ${ }^{2} \mathrm{D}-\mathrm{NMR}$ and ${ }^{31} \mathrm{P}$ - NMR study. Gen. Physiol. Biophys. 2, 457-471
Pan J., Tristram-Nagle S., Kučerka N., Nagle J. F. (2008): Temperature dependence of structure, bending rigidity, and bilayer interactions of dioleoylphosphatidylcholine bilayers. Biophys. J. 94, 117-124; doi:10.1529/biophysj.107.115691

Paterson S. J., Butler K. W., Huang P., Labelle J., Smith I. C., Schneider H. (1972): The effects of alcohols on lipid bilayers: a spin label study. Biochim. Biophys. Acta 266, 597-602; doi:10.1016/0005-2736(72)90356-2

Pope J. M., Walker L., Dubro D. W. (1984): On the ordering of n-alkane and $\mathrm{n}$-alcohol solutes in phospholipid bilayer model membrane systems. Chem. Phys. Lipids 35, 259-277; doi:10.1016/0009-3084(84)90051-3

Pope J. M., Dubro D. W. (1986): The interaction of n-alkanes and nalcohols with lipid bilayer membranes: ${ }^{2} \mathrm{H}-\mathrm{NMR}$ study. Biochim. Biophys. Acta 858, 243-253; doi:10.1016/00052736(86)90329-9

Pringle M. J., Brown K. B., Miller K. W. (1981): Can the lipid theories of anesthesia account for the cutoff in anesthetic potency in homologous series of alcohols? Mol. Pharmacol. 19, 49-55

Raines D. E., Korten S. E., Hill A. G., Miller K. W. (1993): Anesthetic cutoff in cycloalkanemethanols. A test of current theories. Anesthesiology 78, 918-927; doi:10.1097/00000542199305000-00017

Rapp G., Gabriel A., Dosire M., Koch M. H. J. (1995): A dual detector single readout system for simultaneous small- (SAXS) and wide-angle X-ray (WAXS) scattering. Nucl. Instrum. Methods Phys. Res. A 375, 178-182; doi:10.1016/01689002(94)01542-2

Thewalt J. L., Cushley R. J. (1987): Phospholipid/cholesterol membranes containing $n$ alkanols: a ${ }^{2} \mathrm{H}-\mathrm{NMR}$ study. Biochim. Biophys. Acta 905, 329-338; doi:10.1016/00052736(87)90461-5

Uhríková D., Balgavý P., Rapp G. (2002): Lipid bilayer thickness and surface area in lamellar phases of hydrated mixtures of dipalmitoylphosphatidylcholine and homologs of local anesthetic heptacaine. Mol. Cryst. Liq. Cryst. 373, 201-211; doi:10.1080/713738216

Vávrová K., Zbytovská J., Hrabálek A. (2005): Amphiphilic transdermal permeation enhancers: structure-activity relationships. Curr. Med. Chem. 12, 2273-2291; doi:10.2174/ 0929867054864822

Westerman P. W., Pope J. M., Phonphok N., Doane J. W., Dubro D. W. (1988): The interaction of $n$-alkanols with lipid bilayer membranes: a ${ }^{2}$ H-NMR study. Biochim. Biophys. Acta 939, 64-78; doi:10.1016/0005-2736(88)90048-X

Westerman P. W., Pope J. M. (1991): Ordering and solubility of alkanes and alkanols in phospholipid bilayers: $\mathrm{a}^{2} \mathrm{H}-\mathrm{NMR}$ study of the cut-off effect. Ann. N. Y. Acad. Sci. 625, 757-759; doi:10.1111/j.1749-6632.1991.tb33911.x

Received: March 8, 2010

Final version accepted: August 26, 2010 